\title{
Correction to: Characterising and evaluating dynamic online communities from live microblogging user interactions
}

Hugo Hromic $^{1}$ (D) $\cdot$ Conor Hayes $^{1}$

Published online: 24 September 2019

C) Springer-Verlag GmbH Austria, part of Springer Nature 2019

\section{Correction to:}

\section{Social Network Analysis and Mining (2019) 9:30} https://doi.org/10.1007/s13278-019-0576-8

The original version of the article unfortunately contained an error in Acknowledgements section. Below is the corrected version.

Acknowledgements This publication has emanated from research conducted with the financial support of Science Foundation Ireland (SFI) under Grant Number SFI/12/ RC/2289_P2, co-funded by the European Regional Development Fund.
Publisher's Note Springer Nature remains neutral with regard to jurisdictional claims in published maps and institutional affiliations.

The original article can be found online at https://doi.org/10.1007/ s13278-019-0576-8.

\section{Hugo Hromic}

hugo.hromic@insight-centre.org

Conor Hayes

conor.hayes@insight-centre.org

1 Insight Centre for Data Analytics, NUI Galway, Galway, Ireland 